\title{
Effect of X-ray irradiation on the $F_{1}$ generation of Sitophilus zeamais Motschulsky and the germination rate of maize grain
}

\author{
Sobifagha Princess Bell-Gam, Luke Chinaru Nwosu ${ }^{1 *}$ (D), Kayode David lleke ${ }^{2}$ and Uwaoma Otuodichinma Aguwa ${ }^{3}$
}

\begin{abstract}
Background: The use of X-ray irradiation in the control of the maize weevil, Sitophilus zeamais Motschulsky (Coleoptera: Curculionidae) infesting stored maize was tested at 60, 70 and $80 \mathrm{KeV}$ as part of the international concerted efforts to save maize production and enhance food security. Investigations were done in the laboratory at mean temperature and relative humidity of $29.2^{\circ} \mathrm{C}$ and $75.7 \%$, respectively using three varieties of maize. The possibility that $\mathrm{X}$-ray irradiation can affect the viability of maize grains when planted after weevil control process was also evaluated in the laboratory. Standard methods were used to achieve the specific objectives, and X-ray machine snap constituted the exposure time for each dose.

Results: The results revealed 10\% mortality of adult weevils after $24 \mathrm{~h}$ and $40 \%$ mortality after a period of 7 days. The result indicates moderate effect on mortality. Progressive increase in mortality was recorded as dose increased from 60 to $80 \mathrm{KeV}$. X-ray irradiation at the doses tested did not significantly $(P>0.05)$ restrict $S$. zeamais emergence from maize grains and did not also significantly protect grains against damage and flour production. There was no difference in the pattern of daily emergence of new progenies and pattern of accumulated emergence. The relationship between $\mathrm{X}$-ray irradiation doses and weight of emerging progenies require more specific analysis. Absence of significant difference between the viability of irradiated grains and un-irradiated grains strongly suggests that X-ray irradiation did not adversely affect seed viability, and this gives irradiation technique an opportunity of higher acceptability in agriculture.
\end{abstract}

Conclusions: We recommend $>80 \mathrm{KeV}$ of X-ray irradiation or its incorporation into integrated pest management system in order to achieve effective post-harvest control of the pest.

Keywords: X-ray irradiation, Maize weevil, Viability of maize, Mortality

\section{Background}

Maize (Zea mays L.) grain plays crucial role in human nutrition and unequivocally, it is a source of raw materials for industries (Donald, Gabriel, \& Emmanuel, 2008; Olotuah, 2013; Temitope, 2014). Maize grain is critical in the realisation of food security and therefore should

\footnotetext{
* Correspondence: luke2007ambition@yahoo.com

'Department of Crop and Soil Science, University of Port Harcourt, P.M.B.

5323, Port Harcourt, Rivers State, Nigeria

Full list of author information is available at the end of the article
}

be protected against insect pest attack. The maize weevil, Sitophilus zeamais Motschulsky (Coleoptera: Curculionidae) is a major pest of maize grains in storage. It has the capacity to cause qualitative, economic and agronomic problems through its biological activities on maize (Compton \& Sherington, 1999; Khairnar, Adsule, \& Thakur, 1996; Thanda \& Kevin, 2003). Different control strategies are available to tackle this insect pest in storage. They however differ in merits and limitations, and these differences should form important considerations 
for farmers who wish to reduce storage losses due to $S$. zeamais attack. The use of conventional synthetic insecticides and resistant varieties constitute the major weapons in the fight against infestation and damage by S. zeamais. Chemical insecticides cause health and ecological problems (Ashouri \& Shayesteh, 2009; Fields, 2006; Udo, 2005), whereas resistance in maize is liable to breakdown due to overreliance (Nwosu \& Adedire, 2019). It is therefore necessary to identify alternatives that will address these deficiencies.

Irradiation of seeds or food materials in order to cope with insect pest infestations of stored products is gaining popularity in different countries of the world. Irradiation is free from residues, and the technique is desirable to managers seeking to minimize insect pest infestations while the product is in storage (Espo, Eyidozehi, \& Ravan, 2015; Hallman 2013; Salem, Fouda, Abas, Ali, \& Gabarty, 2014). The technology extends the shelf life of different fruits and vegetables and maintains the quality of the product for a prolonged period of time. The technique is convenient, safe and attractive and does not significantly change the quality of the stored product (Espo et al., 2015; Salem et al., 2014). The specific objectives were to determine the (i) effect of X-ray irradiation on the mortality of $S$. zeamais adults, (ii) effect of X-ray irradiation on the number of $S$. zeamais emerged progenies, (iii) efficacy of X-ray irradiation technique in the protection of stored maize against damage and loss by $S$. zeamais and (iv) effect of X-ray irradiation on grain viability when the grains were planted in the laboratory.

\section{Methods}

\section{Experimental site}

The experiment was carried out in the Crop Protection Laboratory of the Department of Crop and Soil Science,
Faculty of Agriculture, University of Port Harcourt and at the Radiology Department, University of Port Harcourt Teaching Hospital, Rivers State, Nigeria. The average temperature and relative humidity of the sites were $29.2{ }^{\circ} \mathrm{C}$ and $75.7 \%$, respectively.

\section{Insect culture}

A population of parental maize weevil pest from alreadyinfested maize grains were collected from Choba Market, Port Harcourt and introduced in fresh maize samples in four different containers. The initial population of S. zeamais used to start the culture was authenticated by an expert. They were left for 8 days to feed, mate, and lay eggs in the fresh maize samples. On the 8th day of infestation, the parental weevils were sieved out of the plastic containers (height $25 \mathrm{~cm}$; diameter $15 \mathrm{~cm}$ ), dead or alive and the setup was kept under the same experimental conditions (29.2 ${ }^{\circ} \mathrm{C}$ and 75.7\%) until new insects emerged in about 60 days. Newly-emerged adults, 1 to 7 days old were used for the bioassay.

\section{Irradiation of maize varieties at the radiology department}

The X-ray machine used was a high-digital snap and record machine which measures radiation doses in Kilo electron volts $(\mathrm{KeV})$. The machine was handled by an expert at the Radiology Department of University of Port Harcourt Teaching Hospital. Three-hundred (300) grams of each maize variety was separately irradiated (in a snap as exposure time) at 60,70 and $80 \mathrm{KeV}$. The action was displayed by a computer connected to the Xray machine. The irradiated samples were used immediately for the experiments without further storage. The maize varieties were yellow maize, flour maize and dent maize obtained from Jos, Nigeria. They were properly

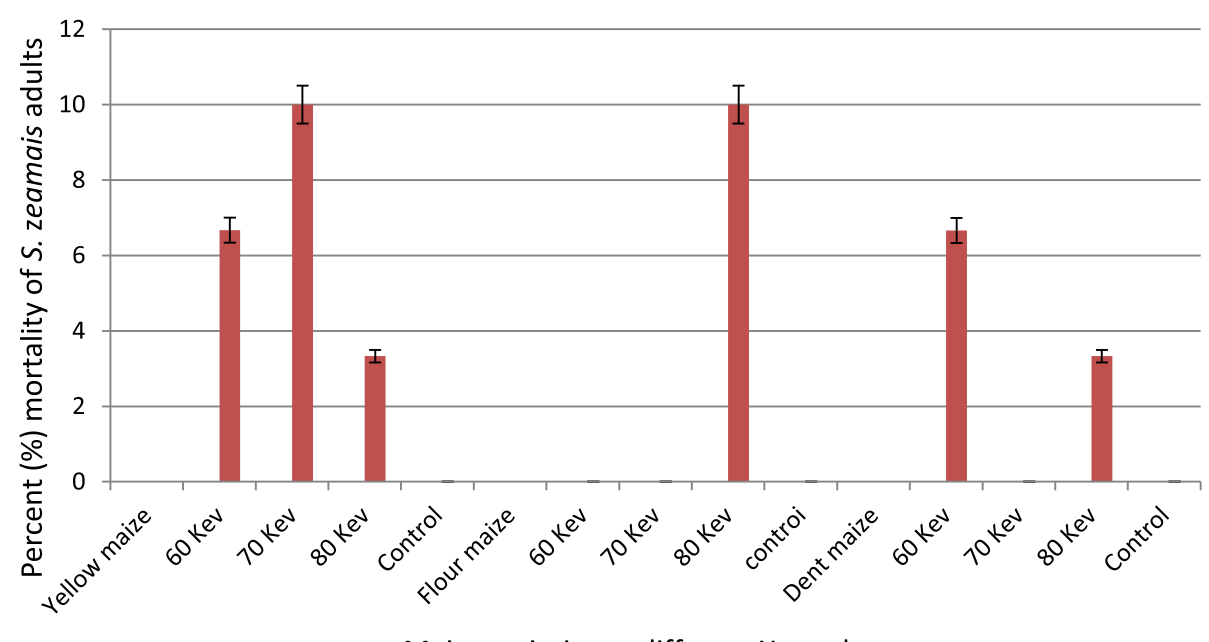

Maize varieties at different $\mathrm{X}$-ray doses

Fig. 1 Effect of X-ray exposure dose (KeV) on the mortality of Sitophilus zeamais Motschulsky adults after $24 \mathrm{~h}$ 
Table 1 Regression coefficients on the yellow maize, flour maize and dent maize varieties for effect of X-ray irradiation on the mortality of S. zeamais after $24 \mathrm{~h}$ of exposure

\begin{tabular}{|c|c|c|c|c|c|c|c|c|c|}
\hline \multirow[t]{3}{*}{ Variety } & \multirow{2}{*}{\multicolumn{2}{|c|}{$\frac{\text { Coefficients }^{\mathrm{a}}}{\text { Model }}$}} & & & \multirow{3}{*}{$\begin{array}{l}\text { Standardized coefficients } \\
\text { Beta }\end{array}$} & \multirow{3}{*}{$\mathbf{t}$} & \multirow{3}{*}{ Sig. } & \multirow{2}{*}{\multicolumn{2}{|c|}{ Collinearity statistics }} \\
\hline & & & \multicolumn{2}{|c|}{ Unstandardized coefficients } & & & & & \\
\hline & & & B & Std. error & & & & Tolerance & VIF \\
\hline \multirow[t]{2}{*}{ Yellow maize } & 1 & (Constant) & .712 & 3.784 & & .188 & .868 & & \\
\hline & & Kev & .082 & .062 & .681 & 1.317 & .319 & 1.000 & 1.000 \\
\hline \multirow[t]{2}{*}{ Flour maize } & 1 & (Constant) & -1.226 & 5.164 & & -.237 & .834 & & \\
\hline & & Kev & .071 & .085 & .510 & .839 & .490 & 1.000 & 1.000 \\
\hline \multirow[t]{2}{*}{ Dent maize } & 1 & (Constant) & .580 & 3.489 & & .166 & .883 & & \\
\hline & & Kev & .037 & .057 & .412 & 639 & .588 & 1.000 & 1.000 \\
\hline
\end{tabular}

${ }^{a}$ Dependent variable: mortality

cleaned to remove any unwanted material before irradiation.

\section{Determination of the effects of X-ray irradiation on mortality, adult emergence, seed damage and flour production caused by $S$. zeamais}

An amount of $20 \mathrm{~g}$ of each of the maize varieties separately irradiated/ exposed to 60,70 and $80 \mathrm{KeV}$ in a snap were put in a plastic container $(11 \mathrm{~cm}$ diameter and $4.5 \mathrm{~cm}$ height) in three replicates and a control designated, laid on a laboratory bench in a randomized complete block design. Five pairs $(5 \circ+$ $5 \hat{\jmath}$ ) of newly emerged (1 to 7 days old) $S$. zeamais adults (not irradiated) were introduced to each of the transparent plastic containers for feeding and oviposition. Male and female weevils were sexed morphologically with the aid of a stereoscope according to Halstead (1963). Sitophilus zeamais adults with comparatively shorter, wider and rougher rostrum were identified as male, while those having longer, narrower, smoother and shinier rostrum were identified as female. Each container was covered with muslin cloth (held in place with cut container-lid) to allow for ventilation and to prevent exit of the weevils and entry of intruders. After 7 days of introduction, the number of dead adults was counted and recorded. Dead adults were those that did not respond to a probe with a pin. Percent mortality was calculated using the standard formula:

\section{Number of dead S.zeamais adults X 100 \\ Total number of S.zeamais adults}

All dead and live S. zeamais adults were sieved out immediately after mortality count leaving behind their

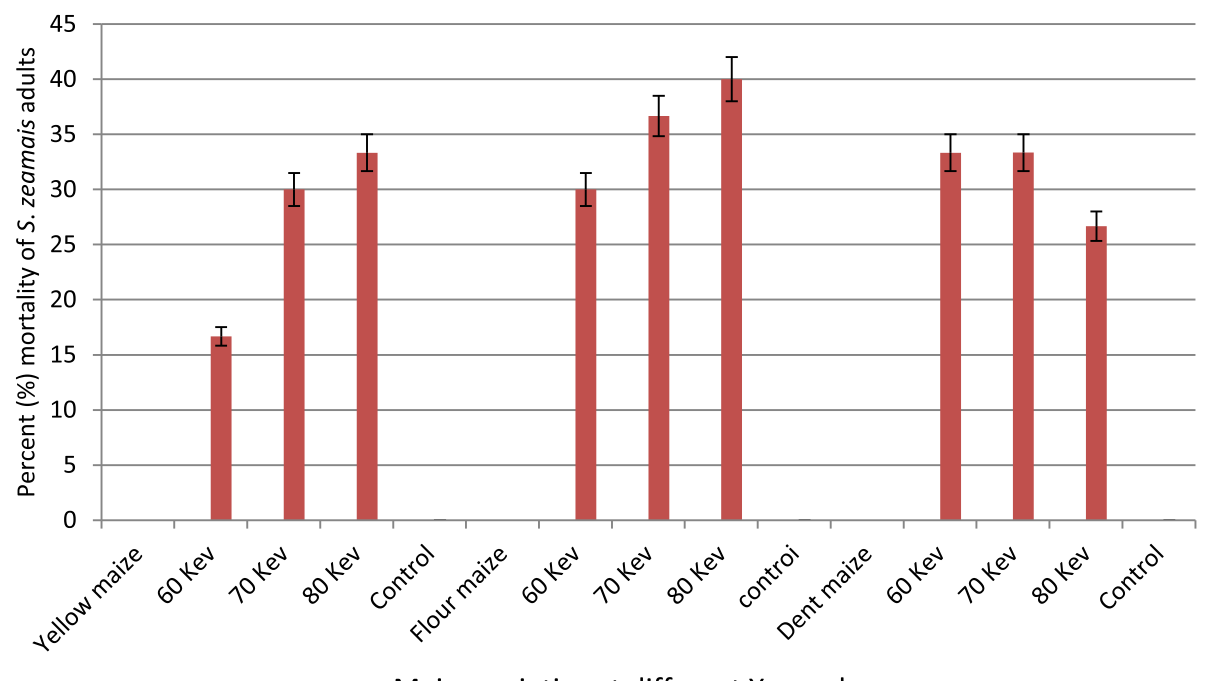

Maize varieties at different X-ray doses

Fig. 2 Effect of X-ray exposure dose (KeV) on the cumulative mortality of Sitophilus zeamais Motschulsky adults after $168 \mathrm{~h}$ (7 days) 
Table 2 Regression coefficients on the yellow maize, flour maize and dent maize varieties for effect of X-ray irradiation on the mortality of S. zeamais after $168 \mathrm{~h}$ (7 days) of exposure

\begin{tabular}{|c|c|c|c|c|c|c|c|c|c|}
\hline \multirow[t]{3}{*}{ Variety } & \multirow{2}{*}{\multicolumn{2}{|c|}{$\frac{\text { Coefficients }^{\mathrm{a}}}{\text { Model }}$}} & & & \multirow{3}{*}{$\begin{array}{l}\text { Standardized coefficients } \\
\text { Beta }\end{array}$} & \multirow{3}{*}{$T$} & \multirow{3}{*}{ Sig. } & \multirow{2}{*}{\multicolumn{2}{|c|}{ Collinearity statistics }} \\
\hline & & & \multicolumn{2}{|c|}{ Unstandardized coefficients } & & & & & \\
\hline & & & $B$ & Std. error & & & & Tolerance & VIF \\
\hline \multirow[t]{2}{*}{ Yellow maize } & 1 & (Constant) & 2.453 & 14.248 & & .172 & .879 & & \\
\hline & & Kev & .191 & .233 & .502 & .820 & .498 & 1.000 & 1.000 \\
\hline \multirow[t]{2}{*}{ Flour maize } & 1 & (Constant) & .842 & 4.102 & & .205 & .856 & & \\
\hline & & Kev & .460 & .067 & .979 & 6.846 & .021 & 1.000 & 1.000 \\
\hline \multirow[t]{2}{*}{ Dent maize } & 1 & (Constant) & .470 & 2.507 & & .187 & .869 & & \\
\hline & & Kev & .499 & .041 & .993 & 12.148 & .007 & 1.000 & 1.000 \\
\hline
\end{tabular}

${ }^{a}$ Dependent variable: mortality

eggs. The infested grains were maintained under the same laboratory conditions as the insect cultures. Thirty days after $S$. zeamais introduction, the number of emerged adult from grains were counted daily until emergence of $F_{1}$ progenies stopped. Association between the weight of emerged adults and X-ray intensity $(\mathrm{KeV})$ was sought electronically using scatter plots. Damaged seeds were also recorded. Damage was characterized in terms of holes and tunnels and was expressed in percent. The weight of maize flour due to S. zeamais activity in the grain was directly weighed on an electronic weighing machine.

\section{Determination of the effect of X-ray irradiation on seed viability}

A total of 10 seeds per variety which were irradiated with X-ray separately at 60,70 and $80 \mathrm{KeV}$, but not infested, were randomly chosen from the $20 \mathrm{~g}$ sample and used for the agronomic experiment. The seeds were placed separately on a moistened Whatman filter paper (110 $\mathrm{mm}$ diameter) inside a transparent plastic container (height $4.5 \mathrm{~cm}$; diameter $11 \mathrm{~cm}$ ), and $10 \mathrm{ml}$ of distilled water was added. The experiment was monitored daily to augment moisture level for a period of 7 days. On the 7 th day, the number of germinated seeds was recorded and compared statistically with the control. There were three replications.

\section{Statistical analysis}

Mortality and progeny emergence data were subjected to regression analysis using the Statistical Package for the Social Sciences (SPSS) version 17.0. Data on percent seed damage and weight of flour caused by the insect were subjected to analysis of variance (ANOVA), and significantly different means were separated using least significant difference (LSD) at $\alpha=0.05$.

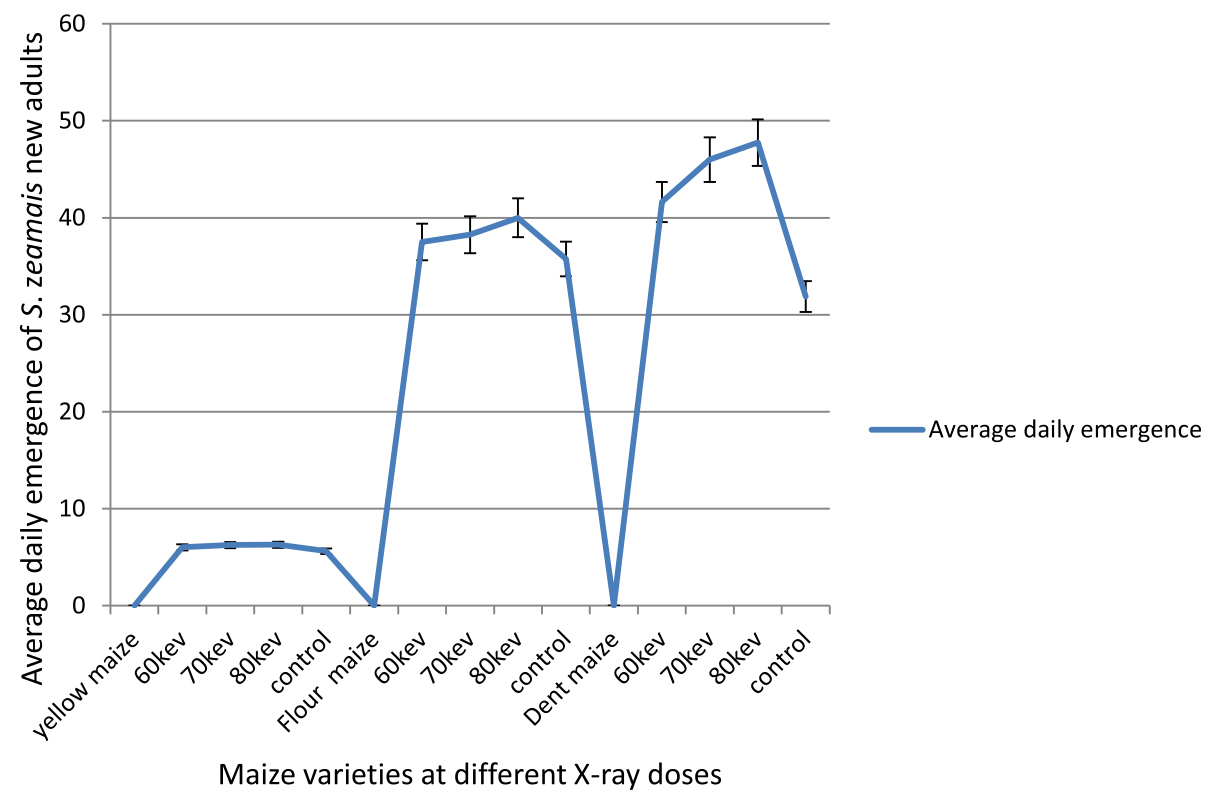

Fig. 3 Effect of X-ray exposure dose (KeV) on the daily emergence of new Sitophilus zeamais Motschulsky adults from three varieties of maize 
Table 3 Regression coefficients on the yellow maize, flour maize and dent maize varieties for effect of X-ray irradiation on the daily emergence of new progenies of S. zeamais after exposure

\begin{tabular}{|c|c|c|c|c|c|c|c|c|c|}
\hline \multirow[t]{3}{*}{ Variety } & \multicolumn{2}{|c|}{ Coefficients $^{\mathrm{a}}$} & & & \multirow{3}{*}{$\begin{array}{l}\text { Standardized coefficients } \\
\text { Beta }\end{array}$} & \multirow{3}{*}{$t$} & \multirow{3}{*}{ Sig. } & \multirow{2}{*}{\multicolumn{2}{|c|}{ Collinearity statistics }} \\
\hline & \multicolumn{2}{|c|}{ Model } & \multicolumn{2}{|c|}{ Unstandardized coefficients } & & & & & \\
\hline & & & $B$ & Std. error & & & & Tolerance & VIF \\
\hline \multirow[t]{2}{*}{ Yellow maize } & 1 & (Constant) & 245.346 & 34.052 & & 7.205 & .019 & & \\
\hline & & Kev & -3.371 & .558 & -.974 & -6.042 & .026 & 1.000 & 1.000 \\
\hline \multirow[t]{2}{*}{ Flour maize } & 1 & (Constant) & 6.557 & 3.315 & & 1.978 & .187 & & \\
\hline & & Kev & .453 & .054 & .986 & 8.340 & .014 & 1.000 & 1.000 \\
\hline \multirow[t]{2}{*}{ Dent maize } & 1 & (Constant) & .918 & 3.319 & & .277 & .808 & & \\
\hline & & Kev & .627 & .054 & .993 & 11.533 & .007 & 1.000 & 1.000 \\
\hline
\end{tabular}

a Dependent variable: daily emergence

\section{Results}

Effect of X-ray irradiation on the mortality of S. zeamais adults

Figure 1 presents the results of the effect of X-ray irradiation on the mortality of $S$. zeamais adults after $24 \mathrm{~h}$ (Yellow maize: $Y=0.712+0.082 X \mathrm{KeV}$; Flour maize: $Y=-$ $1.226+0.0071 X \mathrm{KeV}$; Dent maize: $Y=0.580+0.037 X$ $\mathrm{KeV})$. Table 1 presents the regression coefficients for observations on yellow maize, flour maize and dent maize varieties, respectively. In all the varieties, increase in X-ray dose increased mortality in $24 \mathrm{~h}$. The range of X-ray exposure rates investigated killed maximum of $10 \%$ of the adult weevils after $24 \mathrm{~h}$. In the flour maize variety, there was no adult mortality at 60 and $70 \mathrm{KeV} \mathrm{X}$-ray exposure doses. Figure 2 shows the effect of X-ray dose $(\mathrm{KeV})$ on the cumulative mortality of $S$. zeamais adults after $168 \mathrm{~h}$ (Yellow maize: $Y=2.453+0.191 X \mathrm{KeV}$; Flour maize: $Y=$ $0.842+0.460 X \mathrm{KeV}$; Dent maize: $Y=0.470+4.99 X \mathrm{KeV})$.
Table 2 presents the regression coefficients for observations on yellow maize, flour maize and dent maize varieties, respectively. In all the varieties, increase in X-ray dose increased mortality after 168 h. After 168 h (i.e. 7 days) of exposure to different X-ray doses, at most $40 \%$ of the adult weevils were killed. In the yellow and flour varieties in particular, increase in X-ray exposure rates (from 60 to $80 \mathrm{KeV}$ ) led to a progressive increase in the mortality of the adult insects.

\section{Effect of X-ray irradiation on S. zeamais adult emergence from grains}

The effect of X-ray irradiation on daily emergence of new S. zeamais progeny is summarized in Fig. 3 (Yellow maize: $Y=245.346-3.371 X \mathrm{KeV}$; Flour maize: $Y=$ $6.557+0.453 X \mathrm{KeV}$; Dent maize: $Y=0.918+0.627 X$ $\mathrm{KeV})$. Table 3 presents the regression coefficients for observations on yellow maize, flour maize and dent maize

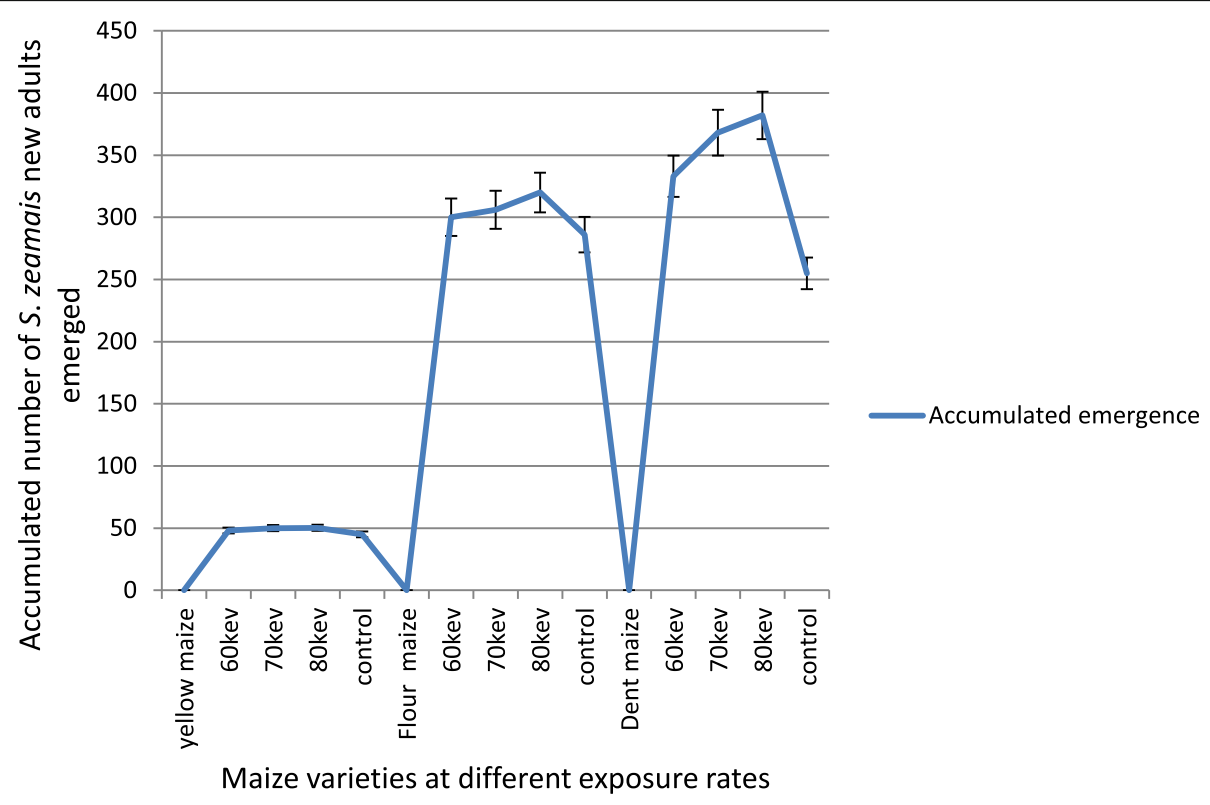

Fig. 4 Effect of X-ray exposure dose (KeV) on accumulated emergence of new Sitophilus zeamais Motschulsky adults from three varieties of maize 
Table 4 Regression coefficients on the yellow maize, flour maize and dent maize varieties for effect of X-ray irradiation on the accumulated emergence of new progenies of $\mathrm{S}$. zeamais after exposure

\begin{tabular}{|c|c|c|c|c|c|c|c|c|c|}
\hline \multirow[t]{3}{*}{ Variety } & \multicolumn{2}{|c|}{ Coefficients $^{\mathrm{a}}$} & & & \multirow{3}{*}{$\begin{array}{l}\text { Standardized coefficients } \\
\text { Beta }\end{array}$} & \multirow{3}{*}{$t$} & \multirow{3}{*}{ Sig. } & \multirow{2}{*}{\multicolumn{2}{|c|}{ Collinearity statistics }} \\
\hline & \multicolumn{2}{|c|}{ Model } & \multicolumn{2}{|c|}{ Unstandardized coefficients } & & & & & \\
\hline & & & $B$ & Std. error & & & & Tolerance & VIF \\
\hline \multirow[t]{2}{*}{ Yellow maize } & 1 & (Constant) & 32.262 & 1.459 & & 22.110 & .002 & & \\
\hline & & Kev & .244 & .024 & .991 & 10.198 & .009 & 1.000 & 1.000 \\
\hline \multirow[t]{2}{*}{ Flour maize } & 1 & (Constant) & 52.508 & 26.518 & & 1.980 & .186 & & \\
\hline & & Kev & 3.624 & .434 & .986 & 8.341 & .014 & 1.000 & 1.000 \\
\hline \multirow[t]{2}{*}{ Dent maize } & 1 & (Constant) & 282.275 & 14.443 & & 19.545 & .003 & & \\
\hline & & Kev & 1.143 & .237 & .960 & 4.828 & .040 & 1.000 & 1.000 \\
\hline
\end{tabular}

a Dependent variable: accumulated emergence

varieties, respectively. In the yellow maize variety, increase in X-ray dose reduced the daily emergence of new $S$. zeamais progeny. The result shows that the doses tested did not reduce the daily emergence of new progenies in flour maize and dent maize varieties. The daily emergence data appeared relatively uniform in the yellow maize variety and in all the three varieties tested; there was no significant difference in the rate of progeny emergence between the X-ray irradiated samples and control. Accumulated emergence (Fig. 4) was not adversely affected by $\mathrm{X}$-ray irradiation too (Yellow maize: $Y=32.262+0.244 X \mathrm{KeV}$; Flour maize: $Y=52.508+$ 3.624X KeV; Dent maize: $Y=282.275+1.143 X \mathrm{Kev})$. Table 4 present the regression coefficients for observations on yellow maize, flour maize and dent maize varieties, respectively.

\section{Association between X-ray exposure dose and weight of emerged adults}

Figure 5 presents the results of association between $\mathrm{X}$-ray exposure dose and weight of $S$. zeamais adults at emergence. The result showed weak positive association between X-ray exposure dose and weight of the insect at emergence.

\section{Effect of X-ray irradiation on seed protection and flour suppression against $S$. zeamais}

Table 5 shows the results on the effect of X-ray irradiation on percent seed damage and flour production. Xray irradiation caused reduction in seed damage and flour production. There was no significant difference $(P$ $>0.05$ ) between the percent seed damage and flour production across all doses tested and in comparison with untreated seeds (i.e. control at $0 \mathrm{KeV}$ ).

Effect of X-ray irradiation on the viability of maize grains Table 6 shows the effect of X-ray irradiation on the germination rate of maize grains planted in the laboratory. At the lowest dose of $60 \mathrm{KeV}$, at least $60 \%$ of the seeds germinated, reaching its peak in the flour maize variety with $86.67 \%$ germination. At highest test dose of 80 $\mathrm{KeV}$, at least $80 \%$ of the irradiated seeds germinated.

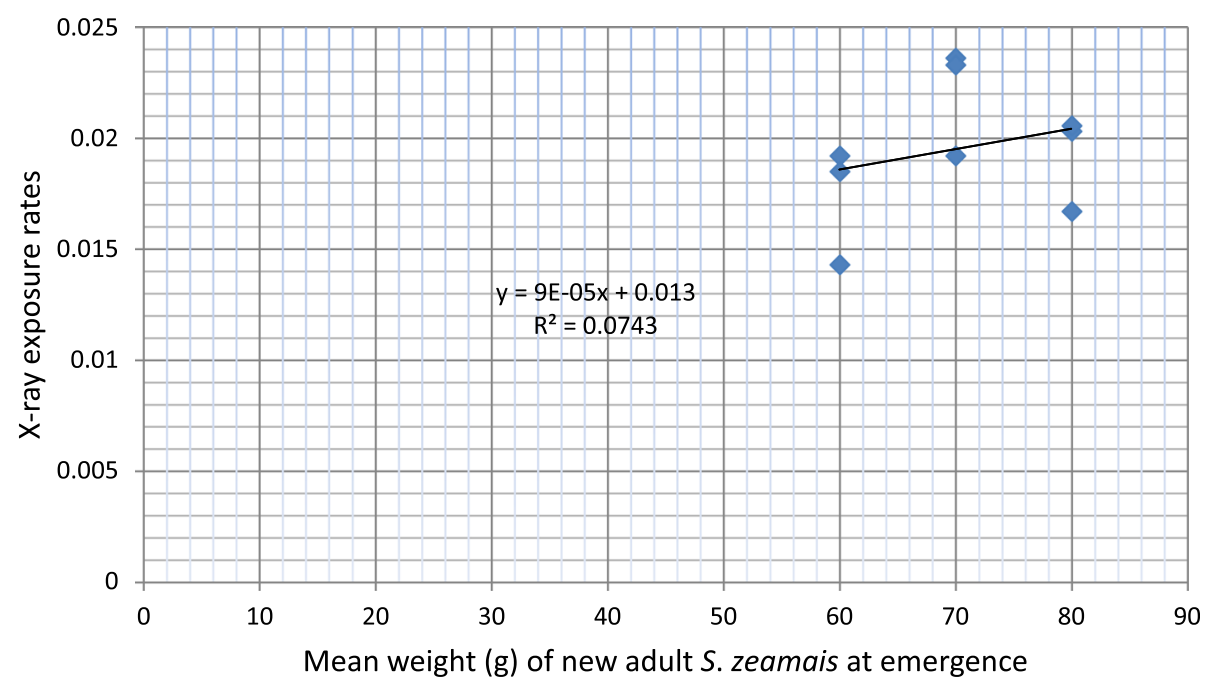

Fig. 5 Association between X-ray exposure dose and weight of Sitophilus zeamais adults at emergence from maize grains 
Table 5 Effect of X-ray irradiation on percent seed damage and flour production caused by S. zeamais Motschulsky

\begin{tabular}{lll}
\hline X-ray exposure dose $(\mathrm{KeV})$ & \% Damage & Quantity of flour (g/ 20 g maize) \\
\hline Yellow maize & & $1.855 \pm 0.00^{\mathrm{a}}$ \\
60.00 & $22.95 \pm 1.50^{\mathrm{a}}$ & $1.924 .00 \pm 0.00^{\mathrm{a}}$ \\
70.00 & $23.33 \pm 0.05^{\mathrm{a}}$ & $2.00 \pm 0.00^{\mathrm{a}}$ \\
80.00 & $23.33 \pm 1.80^{\mathrm{a}}$ & $2.14 \pm 0.00^{\mathrm{a}}$ \\
Control & $31.71 \pm 4.70^{\mathrm{a}}$ & $1.505 \pm 0.001^{\mathrm{a}}$ \\
Flour maize & & $1.621 \pm 0.00^{\mathrm{a}}$ \\
60.00 & $17.67 \pm 1.00^{\mathrm{a}}$ & $1.895 \pm 0.00^{\mathrm{a}}$ \\
70.00 & $18.19 \pm 2.50^{\mathrm{a}}$ & $2.021 \pm 0.00^{\mathrm{a}}$ \\
80.00 & $17.24 \pm 3.02^{\mathrm{a}}$ & \\
Control & $24.29 \pm 0.05^{\mathrm{a}}$ & $2.232 \pm 0.001^{\mathrm{a}}$ \\
Dent maize & & $1.892 \pm 0.00^{\mathrm{a}}$ \\
60.00 & $24.76 \pm 4.00^{\mathrm{a}}$ & $2.026 \pm 0.00^{\mathrm{a}}$ \\
70.00 & $18.10 \pm 5.00^{\mathrm{a}}$ & $2.026 \pm 0.001^{\mathrm{a}}$ \\
80.00 & $28.10 \pm 1.10^{\mathrm{a}}$ & \\
Control & $32.29 \pm 2.50^{\mathrm{a}}$ & \\
\hline
\end{tabular}

Data are means \pm SEM of three replications

Mean values in a column with same letter are not significantly different by LSD $(a=0.05)$

* Not irradiated with X-ray

\section{Discussion}

This study has investigated the possibility of X-ray irradiation to restrict the survival and development of $S$. zeamais, while evaluating the effect of X-ray exposure on seed viability. This step is fundamental because any effective strategy against the maize weevil pest should

Table 6 Effect of X-ray irradiation on the viability of un-infested maize grains in Port Harcourt, Nigeria during 2019

\begin{tabular}{ll}
\hline X-ray exposure rate $(\mathrm{KeV})$ & \% Germination \\
\hline Yellow maize & \\
60.00 & $80.00 \pm 0.00^{\mathrm{a}}$ \\
70.00 & $70.00 \pm 0.00^{\mathrm{a}}$ \\
80.00 & $73.33 \pm 5.00^{\mathrm{a}}$ \\
Control $^{*}$ & $90.00 \pm 0.00^{\mathrm{a}}$ \\
Flour maize & \\
60.00 & $86.67 \pm 12.500^{\mathrm{a}}$ \\
70.00 & $70.00 \pm 6.30^{\mathrm{a}}$ \\
80.00 & $50.00 \pm 13.00^{\mathrm{b}}$ \\
Control & $73.33 \pm 0.00^{\mathrm{a}}$ \\
Dent maize & \\
60.00 & $60.00 \pm 0.00^{\mathrm{a}}$ \\
70.00 & $53.33 \pm 0.00^{\mathrm{a}}$ \\
80.00 & $60.00 \pm 0.00^{\mathrm{a}}$ \\
Control & $50.00 \pm 0.00^{\mathrm{a}}$ \\
\hline
\end{tabular}

Data are means \pm SEM of three replications

Mean values in a column with same letter are not significantly different by $\operatorname{LSD}(a=0.05)$

${ }^{*}$ Not irradiated with X-ray give the seeds an opportunity to germinate after the weevil control process. With the analysis done, it is now possible to understand the patterns of response of irradiated grains to some insect activities. The analyses of results revealed moderate performance of X-ray irradiation in protecting stored maize against $S$. zeamais infestation. Moderate insect mortality caused by X-ray irradiation in the present study suggests good impact because irradiation is a phytosanitary measure. Irradiation does not kill insect pests right after application (Donahaye, 2000). In other words, high radiation tolerance of many storage insect pests (Follett et al., 2013) suggests that higher doses will be required to cause high mortality in storage insect pests. This agrees with the recommendation of this study. From all indications, it is evident that irradiation is not a direct-impact treatment, and so, $40 \%$ mortality at low doses $(60-80 \mathrm{KeV})$ in 7 days is an indication of good performance because higher doses will be quicker in action and ultimately cause higher mortality. Progressive increase in mortality recorded as dosage increased from 60 to $80 \mathrm{KeV}$ suggests that X-ray irradiation might control the insect at higher doses. Further studies are required to confirm specific lethal dose that will ensure maize security with high degree of confidence. This current assertion is supported by Follett and Hennessey (2007). Irradiation is a viable alternative to chemical insecticides for many crops because chemical insecticides are toxic to life (Espo et al., 2015; Follett et al., 2013; Hallman 2013). Irradiation is a quarantine treatment option and part of the major benefits is sterility or prevention of insects from further development, 
feeding or damage (Follett et al., 2013). The same authors reported that with stored product pests, it is not clear what the target is, whether immediate mortality, sterility or arrested feeding. As part of contribution to knowledge, we evaluated the impact of X-ray irradiation on direct mortality of weevil and examined its effects on emergence of new progenies, maize grain damage and flour production. Espo et al. (2015); Hallman (2013) and Salem et al. (2014) have reported effective management of stored-product insect pests using ionizing radiation, gamma irradiation and gamma and ultraviolet irradiation, respectively to affect reproductive capacities. Interestingly, it has been reported that irradiation of seeds or food commodities to tackle insect pest infestations is safe and convenient (Espo et al., 2015). Already, many countries of the world have adopted its application (Espo et al., 2015; Hallman, 2013; Salem et al., 2014), probably because it is convenient and has potentials for integrated pest management.

Furthermore, the analysis of results suggests that at the doses tested, X-ray irradiation did not restrict $S$. zeamais emergence from maize grains, but it reduced grain damage and flour production from seeds, though not significantly. Therefore, evaluation of higher doses and or incorporation into integrated pest management system is strongly recommended, provided the safety limit is not exceeded. Due to day-specific fluctuations, Lopes, Araújo, Santos, Santos, and Sousa (2016) recommended the analysis of accumulated emergence as against daily emergence. In this study, we considered the two, and did not find any difference in pattern. The relationship between X-ray exposure dose and weight of emerging progenies require more specific analysis. It is notable that $\mathrm{X}$-ray irradiation did not significantly reduce the viability of maize grains when planted in the laboratory. Absence of significant difference between the viability of the irradiated grains and the un-irradiated ones strongly suggests that X-ray irradiation did not adversely affect seed viability. This is another factor in favour of irradiation in insect pest control.

\section{Conclusion}

Greater than $80 \mathrm{Kev}$ of X-ray irradiation or its incorporation into integrated pest management system is required to achieve effective post-harvest control of $S$. zeamais infesting maize grains.

\section{Acknowledgements \\ Dr Usman Zakka (Agricultural Entomologist) University of Port Harcourt, Nigeria and Ugochinyere Ihuoma Nwosu (Statistician) Federal University of Technology, Owerri, Nigeria contributed immensely to the success of this research.}

\section{Authors' contributions}

This research was carried out in collaboration with all authors. LCN conceived, designed the study and wrote the manuscript. SPB collected data. KDI and UOA checked data analysis and reviewed the manuscript draft. The authors approved the final manuscript.

Funding

The authors did not receive any fund from anybody. The research was collectively funded by the authors.

Availability of data and materials

Data collected and analyzed during the current study are available from the corresponding author on sensible request.

\section{Declarations}

Ethics approval and consent to participate

Not applicable.

\section{Consent for publication}

Not applicable.

\section{Competing interests}

The authors declare that they have no competing interests.

\section{Author details}

${ }^{1}$ Department of Crop and Soil Science, University of Port Harcourt, P.M.B. 5323, Port Harcourt, Rivers State, Nigeria. ${ }^{2}$ Department of Biology, Federal University of Technology, Akure, Ondo State, Nigeria. ${ }^{3}$ Department of Crop Science and Horticulture, Nnamdi Azikiwe University, Awka, Anambra State, Nigeria.

Received: 28 June 2020 Accepted: 3 May 2021

Published online: 17 May 2021

\section{References}

Ashouri, S., \& Shayesteh, N. (2009). Insecticidal activities of black pepper and red pepper in powder form on adults of Rhyzopertha dominica (F.) and Sitophilus granarius (L.). Pakistan Entomology, 31(2), 122-127.

Compton, J. A. F., \& Sherington, J. (1999). Rapid assessment methods for stored maize cobs: Weight losses due to insect pests. Journal of Stored Products Research, 35(1), 77-87. https://doi.org/10.1016/S0022-474X(98)00012-5.

Donahaye, E. J. (2000). Current status of non-residual control methods against stored product pests. Crop Protection, 19, 571e576.

Donald, A. U., Gabriel, A. A., \& Emmanuel, I. O. (2008). Toxicity and oviposition deterrence of Piper guineense (Piperaceae) and Monodora myristica (Annonaceae) against Sitophilus zeamais (Motsch.) on stored maize. Journal of Entomology, 5(4), 295-299.

Espo, E., Eyidozehi, K., \& Ravan, S. (2015). Influence of gamma and ultraviolet irradiation on pest control. MAGNT Research Report, 3(2), 319-326.

Fields, P. G. (2006). Effect of Pisum sativum fractions on the mortality and progeny production of nine stored-grain beetles. Journal of Stored Products Research, 42(1), 86-96. https://doi.org/10.1016/j.jspr.2004.11.005.

Follett, P. A., \& Hennessey, M. T. (2007). Confidence limits and sample size for determination of nonhost status in fruits and vegetables to tephritid fruit flies as a quarantine measure. Journal of Economic Entomology, 100, 251e257.

Follett, P. A., Snook, K., Janson, A., Antonio, B., Haruki, A., Okamura, M., \& Bisel, J. (2013). Irradiation quarantine treatment for control of Sitophilus oryzae (Coleoptera: Curculionidae) in rice. Journal of Stored Products Research, 52, 63-67. https://doi.org/10.1016/j.jspr.2012.09.004.

Hallman, G. J. (2013). Control of stored product pests by ionizing radiation. Journal of Stored Products Research, 52, 36-41. https://doi.org/10.1016/j.jspr.2 012.10.001.

Halstead, D. G. H. (1963). External sex differences in stored-products Coleoptera. Bulletin of Entomological Research, 54(1), 119-134. https://doi.org/10.1017/ S0007485300048665.

Khairnar, G. P., Adsule, V. M., \& Thakur, S. G. (1996). Quantitative and qualitative losses caused by $C$. chinensis (L.) in Pigeon pea over different periods of storage. Seed Research, 24, 42-44.

Lopes, L. M., Araújo, A. E. F., Santos, A. C. V., Santos, V. B., \& Sousa, A. H. (2016). Population development of Zabrotes subfasciatus (Coleoptera: Chrysomelidae) in landrace bean varieties occurring in Southwestern Amazonia. Journal of Economic Entomology, 109(1), 467-471. https://doi.org/1 0.1093/jee/tov330. 
Nwosu, L. C., \& Adedire, C. O. (2019). Effects of host resistance and plant-derived insecticides on mortality of Sitophilus zeamais (Coleoptera: Curculionidae) adults in stored maize. International Journal of Tropical Insect Science, 39(2), 165-173. https://doi.org/10.1007/s42690-019-00022-9.

Olotuah, O. F. (2013). Comparative efficacy of insecticidal plants in organic flower carriers for controlling the maize weevil, Sitophilus zeamais. Research WebPub, $1(1), 1-7$

Salem, H. M., Fouda, M. A., Abas, A. A., Ali, W. M., \& Gabarty, A. C. (2014). Effects of gamma irradiation on the development and reproduction of the greasy cutworm, Agrotis ipsilon (Hufn.). Journal of Radiation Research and Applied Sciences, 7(1), 110-115. https://doi.org/10.1016/j.jras.2013.12.007.

Temitope, O. O. (2014). Evaluation of the powder of three medicinal botanicals in the control of maize weevil, Sitophilus zeamais Motschulsky. Nature and Science, 12(11), 184-190.

Thanda, D., \& Kevin, V. P. (2003). Divergent selection for resistance to maize weevil in six maize populations. Crop Science, 43, 2043-2049.

Udo, I. O. (2005). Evaluation of the potential of some local spices as stored grain protectants against the maize weevil Sitophilus zeamais Motschulsky (Coleoptera: Curculionidae). Journal of Applied Science Research and Environmental Management, 9(1), 165-168.

\section{Publisher's Note}

Springer Nature remains neutral with regard to jurisdictional claims in published maps and institutional affiliations.

\section{Submit your manuscript to a SpringerOpen ${ }^{\circ}$ journal and benefit from:}

- Convenient online submission

- Rigorous peer review

- Open access: articles freely available online

- High visibility within the field

- Retaining the copyright to your article

Submit your next manuscript at $\boldsymbol{\nabla}$ springeropen.com 